\title{
DIFERENCIAIS COMPETITIVOS ADOTADOS POR EMPRESAS DE TECNOLOGIA DA INFORMAÇÃO DA CIDADE DE CHAPECÓ/SC E REGIÃO
}

\section{RESUMO}

A busca por melhor posicionamento de mercado e Market share é considerada necessidade vital para a existência,bem como sobrevivência das organizações. Diante de tal realidade, com este estudo buscou-se avaliar como as empresas do setor da tecnologia da informação no município de Chapecó e região aliam os conceitos de competitividade e sustentabilidade empresarial. A coleta de dados baseou-se no retorno da aplicação de um questionário com quinze empresas pertencentes ao Deatec. Para o estudo, utilizou-se a análise de caráter qualitativo, e tabulação dos dados baseados em estatística descritiva. Por meio do estudo, identificaramse as áreas de atuação das empresas, bem como fortes forças competitivas com ampla tendência de crescimento, sendo assim detectado que a sustentabilidade na temática abordada tende a tornar-se fator norteador da competitividade no segmento estudado.

Palavras-Chave: TI - Tecnologia da Informação. Competitividade Organizacional. Sustentabilidade Empresarial. Gestão. 


\section{INTRODUÇÃO}

Em virtude dos avanços tecnológicos, inúmeros são os desafios enfrentados pelas organizações que atuam no setor de Tecnologia da Informação - TI, pois o incessante desenvolvimento e o acesso à competitividade faz com que as mesmas determinem diferentes estratégias e objetivos para se desenvolverem sustentavelmente no mercado. De acordo com a Brasscom (Associação Brasileira das Empresas de Tecnologia da Informação e Comunicação), no ano de 2013, esse segmento representava cerca de 4,5\% do PIB (Produto Interno Bruto) brasileiro.

É possível observar essa realidade no sul do país, especialmente no estado de Santa Catarina. Dados divulgados pelo Sebrae-SC (Serviço Brasileiro de Apoio às Micro e Pequenas Empresas) informam que enquanto a estimativa do segmento de TI foi de alta anual de 9\% a 14\% em 2013, para Santa Catarina, a expectativa de expansão estava entre $20 \%$ a 30\%. Nessa direção,um estudo do Gartner Group - empresa mundial de pesquisa em TI - apontou que o investimento de empresas brasileiras de outros setores em tecnologia deveria somar US\$ 134 bilhões em 2013, representando um aumento de 6\% em relação aos US \$ 126 bilhões de 2012. (ADJORISC, 2013).

Atualmente, o Brasil é considerado o quinto maior mercado mundial de TI, com meta de atingir a terceira posição até 2022. Ainda de acordo com a Brasscom, nos próximos dez anos, a estimativa é que o segmento movimente cerca de $\mathrm{R} \$ 430$ bilhões. Já o Ministério da Ciência,
Tecnologia e Inovação aponta que apenas o mercado brasileiro de software deve crescer $400 \%$ no mesmo período. (FORMIDIA, 2013).

Diante desse cenário, torna-se relevante mencionar que há uma concentração de aproximadamente quarenta empresas que atuam no segmento de TI em Chapecó/SC e região, de acordo com os dados coletados em 2014 junto ao Deatec (Pólo Tecnológico do Oeste Catarinense), sendo que especialmente para este estudo,fora obtido um retorno de quinze empresas, que correspondem ou mesmo representam um total de 37,5\% nesse segmento,pertencentes ao Núcleo ${ }^{1}$ das Empresas de Base Tecnológica da ACIC - Associação Comercial e Industrial de Chapecó/SC e ao Deatec ${ }^{2}$ - Polo Tecnológico do Oeste Catarinense. Desse modo, o objetivo principal deste estudo foi buscar, por meio do recurso de pesquisa quantitativa e qualitativa, conhecer como as empresas de TI de Chapecó/ SC e região aliam a competitividade organizacional com a sustentabilidade empresarial. Justifica-se, assim, a relevância deste estudo, ou seja, o crescimento do setor.

Baseado nos pressupostos apresentados, a revisão bibliográfica discutida no estudo remete aos conceitos de TI, bem como de competitividade empresarial.Também são discutidos neste artigo os aspectos metodológicos utilizados para o estudo, a exemplo da coleta e análise de dados e a apresentação das informações obtidas com a aplicação da pesquisa qualitativa e quantitativa, assim como as interpretações e respostas aos objetivos propostos.

\footnotetext{
${ }^{1}$ Este núcleo corresponde à união de empresas de um mesmo ramo de atividade, ou seja, de tecnologia. Mesmo concorrendo entre si, atuam em conjunto na solução de problemas comuns. A ACIC Chapecó conta atualmente com 11 (onze) Núcleos Setoriais e 6 (seis) Núcleos Multissetoriais.

${ }^{2}$ Reúne empresas do segmento de Base Tecnológica - EBT's com o intuito de fortalecer o setor, gerando, por consequência, um incremento no trabalho, renda, qualificação e inovação tecnológica.
} 


\section{TECNOLOGIA DA INFORMAÇÃO - TI}

Apresentada a introdução do trabalho, em que foram evidenciados o tema e problema definidos, os objetivos gerais e específicos, a justificativa do estudo, a metodologia da pesquisa e a organização do trabalho, parte-se para a fundamentação teórica, que depende, fundamentalmente, da teoria que Beuren (2006) desenvolve no esclarecimento dos fatos que consubstanciam o estudo.

A evolução é algo presente nas organizações e uma das consequências é a presença de meios ligados à informação e ao processamento de dados. Atualmente, pode-se considerar que os gestores buscam o processamento e os dados de forma rápida e segura para a tomada de decisão. Essas buscas desencadeiam a geração de mecanismos que se utilizam da tecnologia da informação, pois a informação de forma segura pode ser considerada como sendo parte do patrimônio organizacional. Neste sentido, a TI pode ser considerada como uma forma estratégica das empresas serem competitivas e atuantes no mercado.

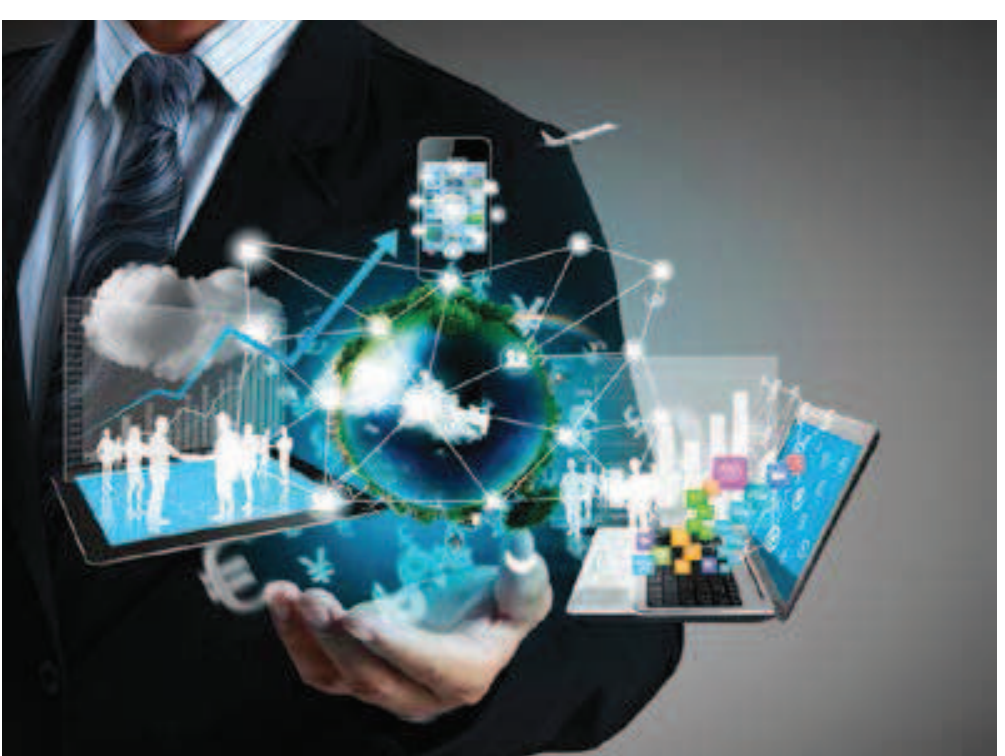

Albertin (2009) afirma que as organizações têm procurado um uso cada vez mais intenso e amplo de TI, não apenas bits, bytes e demais jargões, mas uma poderosa ferramenta empresarial que altere as bases da competitividade e estratégias empresariais. A TI é cada vez mais importante e crescente nas organizações, pois, por meio da usabilidade dessa ferramenta, as empresas têm a capacidade da integração das informações.

De acordo com Laurindo (2007), o conceito de TIé mais abrangente do que os de processamento de dados, sistemas de informação, engenharia de software, informática ou o conjunto de hardware software, pois também envolve aspectos humanos, administrativos e organizacionais. A utilização da TI pelas organizações não deve ser algo subjetivo, mas sim um mecanismo que se adapte às condições, à atividade e aos objetivos empresariais. Segundo Porter e Millar(1985),o valor agregado que uma empresa cria é medido pelo montante que os consumidores desejam pagar por um produto ou serviço.

Para uma organização ser bem sucedida em suas estratégias, deve haver informações válidas e confiáveis que reflitam as medidas de desempenho empresarias, pois sem essas informações, a tomada de decisão será subjetiva e com chances de a empresa não ser bem sucedida em seu TI um conjunto de soluções que processam e armazenam os dados e as informações para a tomada de decisão. 


\subsection{Competitividade}

No mundo empresarial, muito se tem falado em competitividade, estratégias, ações competitivas, vantagens competitivas, dentre outros fatores. Nesse sentido, pode-se dizer que se vivencia um período em que a competitividade pode ser considerada um fator intrínseco ao organizacional.As organizações tornam-se competitivas devido às influências do meio externo, sejam estas de ordem tecnológica,política, econômica ou mesmo empresarial. Diante desses fatores, as organizações necessitam criar estratégias para manterem-se atuantes no mercado e, consequentemente, serem competitivas.

De acordo com Clark e Guy (1998 apud ECIB - Estudo da Competitividade da Indústria Brasileira, 1994) o termo competitividade é geralmente entendido como a habilidade de uma empresa aumentar seu tamanho da fatia de mercado e da lucratividade, ou ainda, como a capacidade da empresa de formular e implementar estratégias concorrenciais que lhe permitam conservar, de forma duradoura, uma posição sustentável no mercado.

A competitividade pode ser considerada como a capacidade de a organização se diferenciar de seus concorrentes. Essa diferenciação pode ser em termos de qualidade do produto ou serviço, preço, familiarização da necessidade de seu consumidor, conhecimento do mercado em que atua, conhecimento das estratégias de seu concorrente e também sintonia com as perspectivas do mercado e da economia.

Portanto, não basta conseguir uma posição de vantagem, é preciso mantê-la ao longo do tempo, torná-la sustentável. Assim, para que uma posição de vantagem possa ser sustentada em longo prazo, a organização necessita saber quais estratégias adotar, bem como se faz necessário o monitoramento das variáveis, implementando estratégias que não possam ser facilmente imitadas pelos concorrentes. (BARNEY, 1991).

No cenário atual de competitividade organizacional, torna-se importante ressaltar alguns fatores determinantes da competitividade das organizações (CLARK; GUY, 1998 apud ESSER et al.,1994), como eficiência, qualidade, flexibilidade, rapidez, sinergia de relacionamentos, capacidade de pesquisa e desenvolvimento, tecnologia, recursos humanos e gestão da inovação.

\subsection{Estratégia Organizacional}

Estratégia organizacional pode ser considerada como sendo a forma de a empresa atuar no mercado em que está inserida, ou seja, a forma de a empresa atuar no mercado para atingir seus objetivos. Alguns autores mencionam que o termo estratégia é bastante antigo, e sua aplicação nos tempos mais remotos consistia em aplicação de forças contra seus concorrentes. O termo estratégia origina-se da palavra grega strategos, significando a arte do general. (OLIVEIRA, 2009).

Dentro do âmbito organizacional, bem como da literatura, o conceito de estratégia é bastante estudado e citado pelos autores, devido a sua referência à forma de atuação da organização. Conforme Porter (1989), o termo consiste na busca de uma posição competitiva favorável em uma indústria, a arena fundamental na qual ocorre a concorrência.

Para Mintzberg, Ahlstrand e Lampel (2000), estratégia é uma palavra que, muitas vezes, é definida de uma forma e usada de outra. Pode-se defini-la como um padrão,ou seja, algo realizado, quando se relaciona ao comportamento passado, mas pode-se, também, definir estratégia como um plano, algo pretendido, ou ainda, olhar para 
frente. Pode-se considerar como estratégia a forma de a organização, a partir de seus dados ou mesmo influências internas ou externas, tomar suas decisões, sejam essas assertivas ou não, ou mesmo competitivas ou não.

Devido ao termo estratégia ser bastante amplo e discutido por vários autores direcionados à linha da administração das empresas, tem-se alguns conceitos sobre as divisões ou mesmo linhas da estratégia. A formulação de uma estratégia competitiva deve ter como base a relação da instituição com seu meio ambiente. Para Porter (2004), o grau de concorrência depende das cinco forças competitivas básicas: barreiras de entrada; ameaça de substituição; poder de negociação dos compradores; poder de negociação dos fornecedores; e rivalidade entre os atuais concorrentes, como ilustra a figura 1 onde Porter (2004,p. 4) esclarece também que:
A meta da estratégia competitiva para uma unidade empresarial em uma indústria é encontrar uma posição dentro dela em que a companhia possa melhor defender-se contra essas forças competitivas ou influenciá-las em seu favor. [...] a chave para o desenvolvi- mento de uma estratégia é pesquisar em maior profundidade e analisar as fontes de cada força.

A figura a seguir ilustra o conjunto das cinco forças competitivas discutidas por Porter (2004), que determina a intensidade da concorrência e a rentabilidade da empresa, sendo que as forças predominantes são essenciais para a formulação de estratégias.

Figura 1: Forças que dirigem a concorrência na indústria

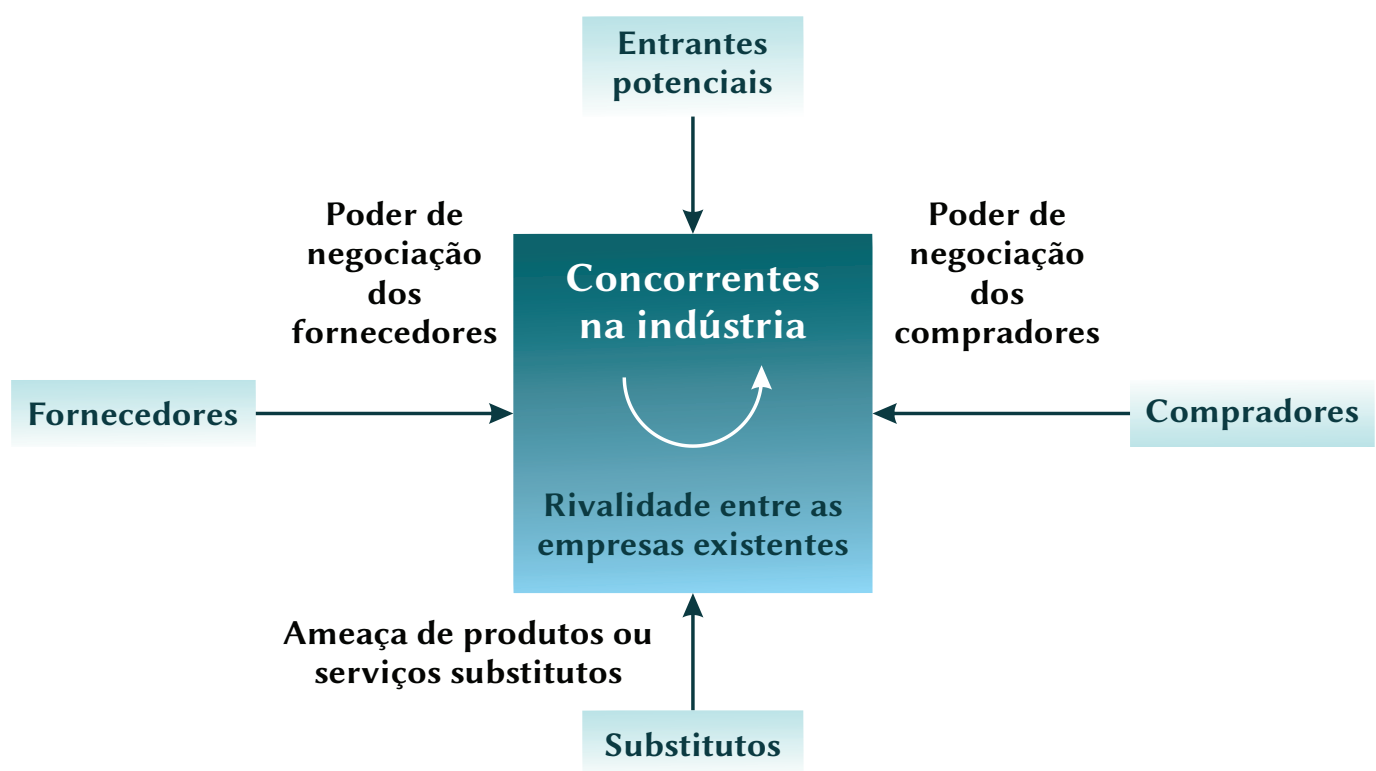

Fonte: Adaptado de Porter (2004, p. 4)

As forças externas à indústria são também importantes, pois afetam todas as empresas do mercado. A diferenciação está na habilidade de cada uma em lidar com essas forças. (PORTER, 2004). Nessa perspectiva, o estudo do ambiente competitivo da organização é fundamental para a formulação da estratégia empresarial, visto que o comportamento competitivo da empresa é intensamente influenciado por essas cinco forças básicas. (AZEVEDO, 2004).

Já no processo de formulação estratégica e sobre a visão baseada em recursos, Barney (1991) desenvolveu tal visão em que a empresa é 
considerada um pacote de recursos tangíveis e intangíveis.Desse modo,Barney (1991) propõe que, para o recurso de uma empresa ter um potencial para uma vantagem competitiva sustentável, ele deve possuir quatro atributos: Valor, Raridade,Inimitabilidade e Substitutibilidade, conhecido como Modelo VRIS.

De acordo com o referido autor, o Modelo VRIS corresponde a uma vantagem competitiva sustentável, na qual o Valor representa os recursos aplicados de forma estratégica na empresa; a Raridade representa os recursos que são considerados diminutos em uma organização; a Inimitabilidade atua na questão de que os recursos não devem ser somente valiosos, mas também difíceis de ser imitados, em que se obtém a vantagem competitiva quando os concorrentes não possuem um recurso ou capacidade e tenham uma necessidade de alto investimento; e a Substitutibilidade é um recurso que pode ser raro e inimitável, mas não será estratégico caso os concorrentes encontrem um substituto para ele, ou seja, não pode possuir um substituto equivalente para este recurso valioso, raro e imitável. (BARNEY, 1991).

A competitividade também pode ser vista pela visão da teoria dos stakeholders, na qual vislumbra-se uma empresa no centro de uma rede de atores, um complexo sistema de troca de mercadorias, serviços, informações, tecnologia, talento, influência, dinheiro e outros recursos. (FREEMAN, 1984). Desse modo, de acordo com Harrison, Bosse e Phillips (2007), o valor da empresa é criado quando esta atende às necessidades das partes consideradas importantes para os seus interessados. Sugere-se que a posição competitiva de uma empresa seja definida por seu pacote exclusivo de recursos e relacionamentos. Assim, identificam-se os atributos desses recursos, que podem fornecer uma fonte de vantagem competitiva sustentável: valiosos, raros e caros para se imitar.(BARNEY, 1991).

Portanto, devido à evolução e globalização dos mercados, em que as organizações buscam ou mesmo tentam aplicar o desenvolvimento sustentável, estreita-se a relação entre os conceitos de competitividade organizacional e sustentabilidade empresarial. Resumidamente, competitividade organizacional representa a capacidade da empresa em gerir seus recursos de forma a concretizar seus objetivos, com vistas a obter a rentabilidade, porém, aliando as ações que venham agir ou praticar atos que vão ao encontro dos preceitos de sustentabilidade empresarial, ou seja, que valorizam e respeitem o meio ambiente.

\section{PROCEDIMENTOS METODOLÓGICOS}

Os procedimentos metodológicos constituíram-se em cinco etapas: a) levantamento das empresas pertencentes ao Núcleo Tecnológico e/ou a Deatec da região limitada de estudo; b) desenvolvimento e aplicação dos questionários estruturados para as empresas entrevistadas; c) pesquisa documental direcionada à revisão bibliográfica; d) análise dos dados e, por fim, e) principais conclusões.
Desse modo, a pesquisa de campo aconteceu no período de 26 de abril a 10 de maio de 2013, buscando analisar as estratégias competitivas utilizadas pelas empresas de TI no município de Chapecó e região. Chapecó exerce, de fato, a função de Capital do Oeste Catarinense, considerada polo de uma região com mais de duzentos municípios, e concentrando mais de um milhão de habitantes, onde se encontram 
principalmente as sedes das principais empresas processadoras e exportadoras de suínos, aves e derivados do Brasil.

Nesse sentido, Chapecó atrai várias empresas, a exemplo das que atuam com o segmento de TI, sendo que, na região oeste de Santa Catarina, há quarenta empresas de TI filiadas a Deatec. Dessas, quinze empresas são de Chapecó. Já quanto às associadas ao Núcleo, tem-se 24 empresas exclusivamente de Chapecó, enfatizando que há empresas que estão associadas em ambas as organizações.

A caracterização do estudo como pesquisa exploratória normalmente ocorre quando há pouco conhecimento sobre a temática a ser abordada. Por meio do estudo exploratório, conforme Beuren (2006), busca-se conhecer com maior profundidade o assunto, de modo a torná-lo mais claro ou construir questões importantes para a condição da pesquisa. Uma característica interessante sobre a pesquisa exploratória consiste no aprofundamento de conceitos preliminares sobre determinada temática não contemplada de modo satisfatório. Assim, contribui para o esclarecimento de questões superficialmente abordadas sobre o assunto.

\subsection{INSTRUMENTO PARA COLETA DE DADOS}

O estudo compreendeu a aplicação de um questionário estruturado com questões iniciais, visando traçar o perfil das empresas participantes da pesquisa, e um roteiro compreendendo catorze itens para identificar a situação atual da empresa diante do mercado. Para tal, foi considerado o universo de quarenta empresas, sendo que a coleta dos dados realizou-se via meio eletrônico às empresas de TI de Chapecó e região, pertencentes ao Núcleo Tecnológico e/ou a Deatec.

\subsection{OBSERVAÇÕES SOBRE A COLETA DE DADOS}

Obteve-se retorno de 37,5\% da amostra, ou seja, o que corresponde às respostas de quinze empresas filiadas ao Núcleo das Empresas de Base Tecnológica da ACIC, as quais também participam do Deatec. A opção por definir ambas as associações como objeto de estudo deu-se devido à possibilidade de obter maior abrangência da amostra já que pesquisas realizadas por email apesar de serem de fácil abrangência e baixo custo ao mesmo tempo caracterizam-se por ter um baixo retorno.

\subsection{ANÁLISE DOS RESULTADOS}

A análise dos dados obtidos após a coleta obedeceu as seguintes etapas:

a) análise comparativa entre os dados coletados;

b) lançamento em planilha de Excel;

c) desenvolvimento de tabelas e gráficos;

d) importação dos dados para softrware estatístico para análises complementares.

A partir da análise de dados foi possível compreender as informações elencadas e melhor representá-las. Na próxima seção serão apresentados os resultados da pesquisa e a análise dos dados. 


\section{APRESENTAÇÃO DA PESQUISA E ANÁLISE DOS DADOS}

A análise de dados está presente em vários estágios da investigação científica, tornando-se mais formal após o encerramento do processo de coleta de dados. Os procedimentos analíticos acompanham todo o transcorrer do estudo, desde o momento em que verifica-se a pertinência das questões selecionadas ao objeto de pesquisa até as considerações finais.

Dessa forma, a análise dos dados, definida por Beuren (2006), significa trabalhar com o material obtido durante o processo investigatório, ou seja, os questionamentos aplicados, os relatos das observações, os apontamentos do checklist, as transcrições das entrevistas realizadas e os transcritos da documentação das fontes primárias e secundárias.

Nesse aspecto, nas seções subsequentes, comenta-se a respeito de como os dados podem receber tratamento analítico e serem interpretados pelo pesquisador. A seguir, apresenta-se o resultado da pesquisa, sendo que o primeiro questionamento refere-se ao tempo de atuação das empresas no mercado da tecnologia.

Tabela 1: Tempo de atuação no mercado

\begin{tabular}{l|c|c}
\multicolumn{1}{c|}{ Tempo } & Frequência Absoluta & Frequência Relativa \\
\hline De 0 a 3 anos & 2 & $13,00 \%$ \\
\hline De 4 a 7 anos & 1 & $7,00 \%$ \\
\hline De 8 a 10 anos & 2 & $13,00 \%$ \\
\hline Acima de 10 anos & 10 & $67,00 \%$ \\
\hline Total & 15 & $100 \%$ \\
\hline
\end{tabular}

Fonte: Dos autores (2013)

Por meio dos dados coletados, pode-se verificar que, dentre as quinze empresas inseridas na atividade tecnológica que se dispuseram a participar da entrevista, $13 \%$ apresentaram menos de três anos de vida; $7 \%$ entre quatro a sete anos; $13 \%$ entre oito a dez anos; e $67 \%$ com mais de dez anos de atividade no mercado.

Quanto ao número de colaboradores nessas empresas, verificou-se a configuração apresentada na tabela 2 . 
Tabela 2: Número de colaboradores

\begin{tabular}{l|c|c}
\multicolumn{1}{c|}{ Colaboradores } & Frequência Absoluta & Frequência Relativa \\
\hline De $\mathbf{0}$ a $\mathbf{1 0}$ colaboradores & 4 & $27,00 \%$ \\
\hline De $\mathbf{1 1}$ a $\mathbf{2 0}$ colaboradores & 2 & $13,00 \%$ \\
\hline De $\mathbf{2 1}$ a $\mathbf{4 0}$ colaboradores & 4 & $27,00 \%$ \\
\hline De $\mathbf{4 1}$ a $\mathbf{6 0}$ colaboradores & 2 & $13,00 \%$ \\
\hline Acima de $\mathbf{6 0}$ colaboradores & 3 & $20,00 \%$ \\
\hline Total & 15 & $100 \%$ \\
\hline
\end{tabular}

Fonte: Dos autores (2013)

Observa-se quem, dentre o número de colaboradores, tem-se $27 \%$ que possuem até dez colaboradores; $13 \%$ entre onze a vinte; $27 \%$ de 21 a quarenta; $13 \%$ de 41 a sessenta; e $20 \%$ possuem acima de sessenta colaboradores.

Verifica-se que o número de colaboradores das organizações não apresentou relações consideráveis no que diz respeito ao tempo de vida da empresa. Percebe-se, ainda, que o número de colaboradores é considerado baixo, e os gestores/empresários, em sua grande maioria, participam de várias atividades dentro da empresa, como vendas, desenvolvimento e, até mesmo, no suporte aos clientes.

Conforme resultados de uma pesquisa de mapeamento de vagas no setor de TI realizada pela equipe do GeraçãoTec ${ }^{3}$, dentro de um ano, as empresas da região terão potencial para absorver mais de 250 profissionais para atuarem como programadores em diversas linguagens e também para atendimento a clientes e suporte técnico (com suporte/help desk e linguagem Delphi). Seguindo a análise dos fatos, na tabela 3 tem-se a demonstração do ramo de atuação das empresas de tecnologia.

\footnotetext{
${ }^{3}$ Programa que cria oportunidades para jovens e adultos por meio de qualificação profissional.Instituído pelo Governo do Estado/ Secretaria do Desenvolvimento Econômico Sustentável, é executado através da FAPESC, em parceira com instituições do setor de tecnologia e informação.
} 
Tabela 3: Ramo de atuação

\begin{tabular}{l|c|c}
\multicolumn{1}{c|}{ Ramo } & Frequência & Frequência \\
Relativa & Absoluta \\
\hline Comercial (Supermercados, Lojas, Panificadoras etc.) & 5 & $33,00 \%$ \\
\hline Industrial & 2 & $13,00 \%$ \\
\hline Empresarial & 3 & $20,00 \%$ \\
\hline Imobiliário & 1 & $7,00 \%$ \\
\hline Transportes & 1 & $7,00 \%$ \\
\hline Escritórios Contábeis & 2 & $13,00 \%$ \\
\hline Hoteleiro & 1 & $7,00 \%$ \\
\hline Total & 15 & $100 \%$ \\
\hline
\end{tabular}

Fonte: Dos autores (2013)

Com o crescimento tecnológico, a busca e a necessidade pelo uso da informática, verificase um crescimento das empresas da área de tecnologia em vários segmentos.

Verifica-se que, devido a maior concentração de empresas que atuam com ênfase comercial na região pesquisada (supermercados, lojas, dentre outros), constatou-se que a maioria das empresas de TI direciona seus produtos para atender esse segmento. Essa evidência pode demonstrar maior disputa competitiva por parte das empresas de TI da região, aumentando seus esforços competitivos. Porém, percebeu-se que poucas empresas de TI optaram por atuar em outros segmentos de mercado com características mais específicas e diversificados, a exemplo do hoteleiro, de transportes e imobiliário.

Identifica-se, assim, que os esforços competitivos dessas empresas poderiam representar uma vantagem competitiva para quem optar especializar-se nesses nichos.

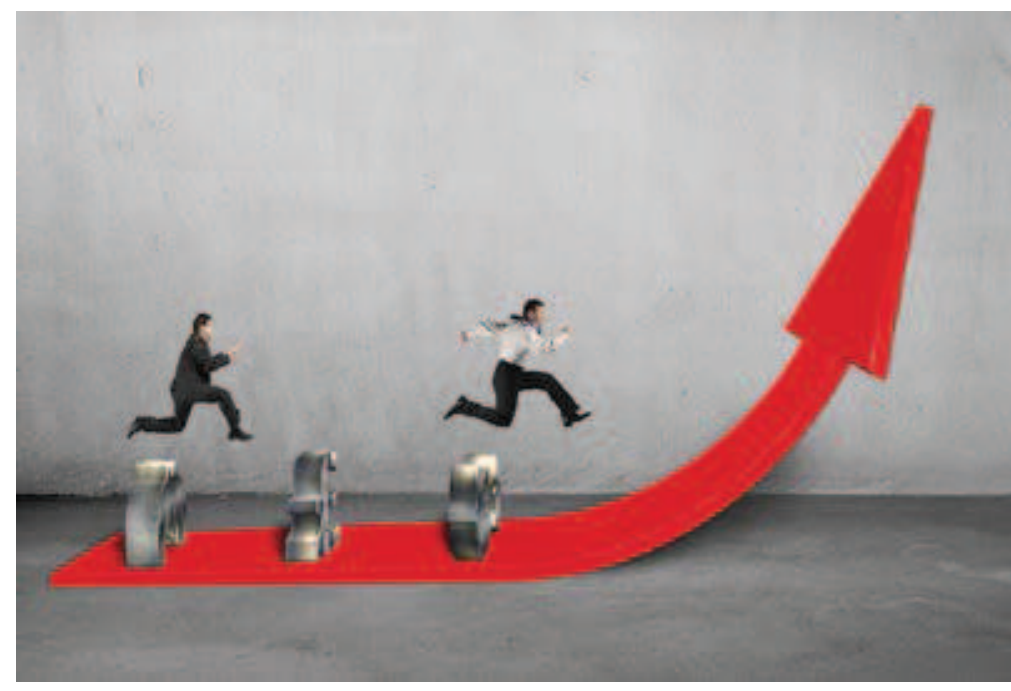

O desenvolvimento de nichos e segmentos específicos pode apresentar a característica de inimitabilidade, em que, de acordo com o proposto por Barney (1991), o recurso deve não só ser valioso, mas também difícil de ser imitado, obtendo-se a vantagem competitiva pelo fato dos concorrentes não possuírem este recurso ou necessidade de alto investimento para especializar-se em um nicho tão específico. $\mathrm{Na}$ tabela 4, buscou-se analisar a situação das empresas diante do mercado atual. 
Tabela 4: Situação atual da empresa diante do mercado

\begin{tabular}{|c|c|c|c|c|}
\hline Descrição & $\begin{array}{c}\text { “" } " \\
\text { Inexistência }\end{array}$ & $\begin{array}{c}\text { "1" } \\
\text { Baixa } \\
\text { existência }\end{array}$ & $\begin{array}{c}\text { "2" } \\
\text { Média } \\
\text { existência }\end{array}$ & $\begin{array}{c}\text { "3" } \\
\text { Alta } \\
\text { existência }\end{array}$ \\
\hline $\begin{array}{l}\text { Facilidade de seu produto ser } \\
\text { imitado. }\end{array}$ & $0,00 \%$ & $47,00 \%$ & $40,00 \%$ & $13,00 \%$ \\
\hline Capacidade de inovação. & $0,00 \%$ & $0,00 \%$ & $27,00 \%$ & $73,00 \%$ \\
\hline Facilidade de acesso a recursos. & $7,00 \%$ & $13,00 \%$ & $33,00 \%$ & $47,00 \%$ \\
\hline $\begin{array}{l}\text { Facilidade de adaptação de sua } \\
\text { empresa e produto ao mercado. }\end{array}$ & $7,00 \%$ & $0,00 \%$ & $27,00 \%$ & $66,00 \%$ \\
\hline $\begin{array}{l}\text { Participação de sua marca no } \\
\text { mercado. }\end{array}$ & $0,00 \%$ & $20,00 \%$ & $47,00 \%$ & $33,00 \%$ \\
\hline $\begin{array}{l}\text { Sintonia dos objetivos da orga- } \\
\text { nização com a sustentabilidade } \\
\text { (social, ambiental, econômico). }\end{array}$ & $7,00 \%$ & $33,00 \%$ & $40,00 \%$ & $20,00 \%$ \\
\hline $\begin{array}{l}\text { Elaboração de planejamento e } \\
\text { projetos. }\end{array}$ & $0,00 \%$ & $7,00 \%$ & $27,00 \%$ & $66,00 \%$ \\
\hline $\begin{array}{l}\text { Oportunidades para a empresa } \\
\text { frente ao mercado. }\end{array}$ & $0,00 \%$ & $0,00 \%$ & $20,00 \%$ & $80,00 \%$ \\
\hline $\begin{array}{l}\text { Relacionamento com os } \\
\text { Stakeholders(clientes, fornecedo- } \\
\text { res, comunidade, colaboradores, } \\
\text { governo, concorrência, outros). }\end{array}$ & $0,00 \%$ & $0,00 \%$ & $53,00 \%$ & $47,00 \%$ \\
\hline Competência da equipe. & $0,00 \%$ & $0,00 \%$ & $53 \%$ & $47,00 \%$ \\
\hline $\begin{array}{l}\text { Capacitação e desenvolvimento } \\
\text { dos colaboradores. }\end{array}$ & $0,00 \%$ & $7,00 \%$ & $40,00 \%$ & $53,00 \%$ \\
\hline Rotatividade de colaboradores. & $7,00 \%$ & $47,00 \%$ & $13,00 \%$ & $33,00 \%$ \\
\hline Ameaças do mercado. & $0,00 \%$ & $33,00 \%$ & $0,00 \%$ & $67,00 \%$ \\
\hline Concorrência. & $0,00 \%$ & $20,00 \%$ & $20,00 \%$ & $60,00 \%$ \\
\hline
\end{tabular}

Fonte: Dos autores (2013) 
Os itens apresentados na tabela 4 estão relacionados à situação atual das empresas pesquisadas frente ao mercado, em que utilizou-se a escala de "0 a 3"; sendo a escala "0" correspondente à inexistência da situação; "1" situação baixa; "2" situação média; e “3" equivalente à situação alta. Desse modo, os gestores deveriam marcar a situação que considerassem serem atuais e representativas para suas organizações.

Quanto à percepção dos gestores pesquisados relacionada à facilidade de seus produtos serem imitados, constatou-se que $47 \%$ acreditam ser baixa a possibilidade; $40 \%$ consideram ser média; e 13\% afirmaram ser alta. Portanto, quanto maior a inimitabilidade dos ativos produtivos da empresa maiores condições de competitividade a mesma poderá usufruir, dispondo de maior lucratividade e participação de mercado em que, nessa questão, evidencia-se a baixa e média condição para o contexto.

Para a capacidade de inovação dessas organizações, $73 \%$ consideram ser alta sua capacidade de inovação; e 27\% consideram média. É importante ressaltar que a inovação, segundo Sahwney, Wolcott e Arroniz (2006), é relevante somente se a mesma criar valor para os consumidores, e, então, para a empresa. Além disso, a criação de "coisas novas" não é nem necessária nem suficiente para a inovação nos negócios. Os consumidores são os únicos que decidem o valor de uma inovação votando com suas carteiras. Não importa o quão inovadora uma empresa pensa que é, pois o que importa, segundo os autores, é se os consumidores irão pagar.

Em relação à facilidade de acesso a recursos, a exemplo de financiamentos, $47 \%$ dos pesquisados consideram ser alta a possibilidade; $33 \%$ consideram média; e 13\% baixa. Essa facilidade poderia representar uma vantagem, porém, a mesma não é acessível a todas as empresas. Sobre a facilidade de adaptação dos produtos, bem como das empresas investigadas, identificou-se que $66 \%$ consideram alta; $27 \%$ média; e $7 \%$ difícil. Pode-se perceber que algumas ainda encontram dificuldades em acompanhar as mudanças no mercado, especialmente por se tratar de tecnologia, a qual está mudando com grande velocidade.

Sobre a participação da marca das empresas de TI investigadas, 47\% consideram sua participação como sendo média; 33\% alta; e 20\% baixa. Desse modo, quanto maior a participação de mercado da organização, maiores serão seus resultados, obtendovantagem competitiva. Porém, não basta conseguir uma posição de vantagem, mas é preciso mantê-la ao longo do tempo e torná-la sustentável.

Quanto à sintonia dos objetivos da organização com a sustentabilidade nos âmbitos social, ambiental e econômico, identificou-se que $40 \%$ consideram média a sintonia; $33 \%$ baixa; $20 \%$ alta; e 7\% inexistente. Este resultado demonstra o quanto ainda as organizações, neste caso em especial as de TI, devem percorrer para atender o que conceitualmente tem-se como definição de sustentabilidade organizacional,ou seja,manterem-se competitivas no mercado em longo prazo com capacidade de sobrevivência e atuação equilibrada com o contexto econômico, financeiro e social.

Já em relação à elaboração de planejamento e projetos, $66 \%$ consideram alta sua capacidade; $27 \%$ média; e $7 \%$ baixa. Ao se questionar sobre as oportunidades que representam para a empresa frente ao atual mercado, identificou-se que $80 \%$ consideram alta; e $20 \%$ média. Em se tratando do relacionamento com os stakeholders (clientes, fornecedores, comunidade, colaboradores, governo, concorrência e outros), 53\% consideram o mesmo como sendo mediano; e 47\% consideram elevado. Tal evidência pode dar indícios de vantagem competitiva desde 
que essas empresas consigam atender às necessidades das partes consideradas importantes dos interessados da empresa, neste caso, seus stakeholders, o que fora apontado pelos autores Harrison, Bosse e Phillips (2007). Portanto, o relacionamento entre os mesmos pode ser considerado positivo, porém se desconhece se as empresas de TI de Chapecó e região estão conseguindo agregarvalor aos seus stakeholders, o que requer outra modalidade de estudo.

Avaliando aspectos internos da organização, sobre a competência da equipe de colaboradores das empresas de TI investigadas, identificou-se que 53\% consideram média; e $47 \%$ alta. Também dentro dos aspectos internos, referindo-se à capacidade e desenvolvimento dos colaboradores, $53 \%$ consideram alta; $40 \%$ média; e 7\% baixa. Em se tratando da rotatividade, a pesquisa revelou que $47 \%$ consideram baixa; $33 \%$ alta; $13 \%$ média; e, para $7 \%$, inexiste tal problemática.

Assim, de acordo com o cenário atual de competitividade organizacional, alguns fatores passam a ser determinantes para a competitividade das organizações, conforme já apontado por Clark e Guy (1998 apud ESSER et al., 1994), como eficiência, qualidade, flexibilidade, rapidez, sinergia de relacionamentos, capacidade de pesquisa e desenvolvimento, tecnologia, recursos humanos e gestão da inovação. E, portanto, de acordo com o resultado da pesquisa, demonstram-se condições favoráveis de competitividade, a exemplo da realização de planejamento e projetos, das oportunidades identificadas no mercado, do relacionamento com os stakeholders e a competência dos colaboradores, que ficaram entre as respostas de média e alta existência.

Em relação ao ambiente externo, questionou-se acerca das ameaças do mercado, em que $67 \%$ consideram alta; e 33\% baixa. Sobre a concorrência, 60\% responderam ser alta; e 20\% consideram média e baixa, respectivamente. Nessa perspectiva, o estudo do ambiente competitivo da organização torna-se fundamental para a formulação da estratégia empresarial, visto que o comportamento competitivo da empresa é intensamente influenciado pelas cinco forças básicas designadas por Porter (1991).

\section{CONSIDERAÇÕES FINAIS}

O presente artigo buscou avaliar os diferenciais competitivos adotados por empresas de TI - Tecnologia da Informação - situadas em Chapecó/SC, sendo este considerado um diferencial no ramo tecnológico. Por meio de pesquisa de campo, buscou-se compreender os fatores norteadores da competitividade de tais empresas e, com base na avaliação dos dados, foi possível evidenciar elementos de discussão favoráveis à competitividade das empresas estudadas.
As particularidades encontradas em termos de recursos apontam que os fatores de competitividade aplicados ao segmento são diferenciados, e é por esse motivo que a raridade e a dependência configuram-se como fatores de sustentação estratégica, essenciais para a promoção de vantagens estratégicas competitivas e sustentáveis. Contudo, esses não podem ser tomados de forma isolada. Sua manutenção, num primeiro momento, resigna-se ao desafio de se manter a alta relação com os stakeholders (clientes, fornecedores, comunidade, colaboradores, governo, concorrência, entre outros). 
Evidenciam-se, no segmento de TI,características de inimitabilidade, em que, de acordo com o proposto por Barney (1991), consequentemente em virtude dos esforços efetuados serem direcionados a segmentos de forma customizada, o recurso deve não só ser valioso, mas também difícil de ser imitado, obtendo-se a vantagem competitiva pelo fato de os concorrentes não possuírem esse recurso ou necessidade de alto investimento para especializar-se em um produto com nicho tão específico. Diante dos dados analisados, observa-se que o segmento de TI é considerado promissor.Assim, constata-se que, em relação aos pesquisados, os segmentos de atuação de TI são diversificados, com potencial de inovação e significativas oportunidades.

Em virtude do exposto, é possível concluir que a aderência entre as forças competitivas e as contribuições de ações sustentáveis são fatores críticos de sucesso dos esforços de competitividade para o segmento de TI, assim como em qualquer outro, ou seja, apresenta as mesmas características. Desse modo, as empresas pesquisadas têm uma boa percepção tanto do valor estratégico de TI como da importância do tratamento adequado de determinados aspectos para aumentar as chances de sucesso de suas organizações.

As empresas, de forma similar em todos os setores, devem buscar cada vez mais as melhores práticas para o tratamento de cada um dos aspectos relacionados às suas forças competitivas e promissoras da sustentabilidade no seu segmento de atuação.

Sendo assim, quanto ao objetivo principal deste estudo, o qual buscou, por meio do recurso de pesquisa quantitativa e qualitativa conhecer como as empresas de TI de Chapecó/SC e região aliam a competitividade organizacional com a sustentabilidade empresarial, pode-se identificar que a maioria das empresas pesquisadas enquadra-se nos itens considerados de alta existência. Dentro desse item, compete especificamente à capacidade de inovação (73,0\%); facilidade de acesso a recursos (47,0\%); facilidade de adaptação da empresa e seus produtos ao mercado (66,0\%); elaboração de planejamento de projetos (66,0\%); oportunidades para a empresa frente ao mercado (80,0\%); relacionamento com seus stakeholders (53\%); e capacidade de desenvolvimento dos seus colaboradores $(53,0 \%)$.

Identificou-se, de acordo com as respostas, que a maioria das empresas pesquisadas julga atuar no mercado de forma competitiva, porém, ainda de uma maneira tímida ao aliar suas estratégias competitivas à sustentabilidade empresarial, a exemplo do fato de que ameaças do mercado (67\%) e a concorrência (60\%) acabam sendo relevantes no contexto competitivo. Assim, além de buscar resultados econômicos, faz-se necessário aliar esta busca com o equilíbrio social e ambiental, mesmo que a atividade de TI não resulte em impactos representativos dentro dessas duas esferas, ficando claro que ainda há um caminho a ser percorrido.

O estudo possibilitou identificar que o segmento de TI é considerado promissor, conforme a expectativa de crescimento e desenvolvimento do setor apresentado. Constata-se,também,em relação aos pesquisados, que a aderência entre as forças competitivas e as contribuições de ações sustentáveis estratégicas são fatores críticos de sucesso dos esforços de competitividade do setor, demonstrando que essas empresas têm uma boa percepção do valor estratégico de TI, devendo buscar, cada vez mais, as melhores práticas para conciliar suas forças competitivas às forças da sustentabilidade empresarial. 
COMPETITIVE

ADVANTAGES

ADOPTED BY

INFORMATION

TECHNOLOGY

COMPANIES OF THE

TOWN OF CHAPECÓ

(SC) AND PROVINCE

ABSTRACT

The search for better market positioning and market share are considered vital needs for existence as well as for survival of organizations. Faced with this reality, with this study we sought to evaluate how companies in the information technology sector in Chapecó and province combine the concepts of competitiveness with corporate sustainability. For data collection, was based our work on feedback from a questionnaire applied in 15 companies belonging to DEATEC. For the study, we used the qualitative analysis, and tabulation of the data based on descriptive statistics. Through the study, we identified areas where the companies operate, as well as strong competitive forces with a large growth trend, so that it was detected that sustainability in the considered scenario tends to become guiding factor of competitiveness in the segment studied.

\section{Keywords: IT - Information \\ Technology. Organizational \\ Competitiveness. Corporate \\ Sustainability. Management.}

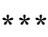

\section{REFERÊNCIAS}

ADJORISC - Associação dos Jornais do Interior de Santa Catarina. Em SC, setor de TI apresenta crescimento médio anual superior a 20\%. Disponível em: < http:// www.adjorisc.com.br/economia/em-sc-setorde-ti-apresenta-crescimento-medio-anualsuperior-a-20-1.1280029\#.VBJaWummfIU >. Acesso em: 28 maio 2013.

ALBERTIN, A. L. Administração de informática: funções e fatores críticos de sucesso. São Paulo: Atlas, 2009.

ALMEIDA, F. O bom negócio da sustentabilidade. Rio de Janeiro: Nova Era, 2002.

BARNEY, J. Firm resources and sustainable competitive advantage. Journal of Management. v. 17, n. 1 , p. $99-120,1991$.

BEUREN, I. (Org.). Como elaborar trabalhos monográficos em contabilidade: teoria e prática. 2. ed. São Paulo: Atlas, 2006.

BRASSCOM. Associação Brasileira das Empresas de Tecnologia da Informação e Comunicação. Disponível em: <http://www.brasscom.org.br/ brasscom/Portugues/detInstitucional. php? codArea=6\&codCategoria=8>. Acesso em: 25 maio 2013.

CLARK, J.; GUY, K. Innovation and Competitiveness: a review. Technology Analysis \& Strategic, Management. v. 10, n. 3, 1998.

DEATEC, Polo Tecnológico do Oeste Catarinense. Disponível em: <http://www.deatec. org.br/index.php?exc $=$ documentos.2 $>$. Acesso em: 20 maio 2013.

ECIB. Estudo da Competitividade da Indústria Brasileira. 2. ed. Campinas: Papirus, 1991.

ESSER, K.; WOLFGANG, H.; MESSNER, D.; MEYER-STAMMER, J. Competitividad Sistémica: Competitividad internacional de las empresas y políticas requeridas. Estudios e Informes. Instituto Alemán de Desarollo: Berlin, 1994.

FORMIDIA. SC: R \$ 3 milhões em negócios na BITS 2013. Disponível em: < http://formidia. com.br/2013/05/sc-r-3-milhoes-em-negocios-nabits-2013/ > Acesso em: 28 maio 2013.

HARRISON, J.; BOSSE, D.; PHILLIPS, R. A. Stakeholder theory and competitive advantage.

IN: Academy of Management Annual Meeting Proceedings. Anais. Academy of Management, 2007. 


\section{SOBRE OS AUTORES}

LAURINDO, F. J. B. Tecnologia da Informação

- Eficácia nas organizações. 2 ed. São Paulo:

Editora Futura, 2007.

LÓSSIO, Rodrigo. Governo de SC investe

$\mathrm{R} \$ 630$ milhões em programas para desenvolvimento sustentável. Disponível em: $<$ http://tisc.com.br/governo/governo-de-scinveste-r-630-milhoes-em-programas-paradesenvolvimento-sustentavel/>. Acesso em: 18 maio 2013.

MINTZBERG, H. AHLSTRAND, B. e LAMPEL, J. Safaria de Estratégia: um roteiro pela selva do planejamento estratégico. Porto Alegre: Bookman, 2000.

NÚCLEOS ACIC. Associação Comercial e Industrial de Chapecó. Disponível em: <http:// www.acichapeco.com.br/nucleos.htm >. Acesso em: 18 maio 2013.

OLIVEIRA, D. P. R. Planejamento Estratégico: Conceitos, metodologia e práticas. São Paulo: Atlas, 2009.

PORTER, Michael E.; MILLAR, Victor E. How Information Gives You Competitive Advantage. Harvard Business Review. Boston, July-August, 1985.

PORTER, Michael E. Estratégia Competitiva: Técnicas para Análise de Indústrias e da Concorrência. 2. ed. Rio de Janeiro: Elsevier, 2004.

Vantagem Competitiva. 12. ed. Rio de Janeiro: Campus, 1989.

SAWHNEY, M.; WOLCOTT, R.; ARRONIZ, I. The 12 ways to innovate. MIT Sloan Management Review. v. 47, n. 3, 2006.

Data de recebimento: $15 / 10 / 13$

Data de aprovação: 29/10/14

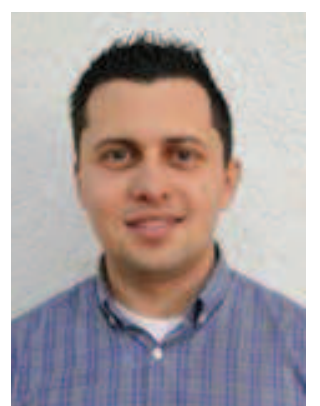

\section{Andrei Bonamigo}

Aluno do Mestrado

Profissional em

Administração da Unoesc com extensão no Mestrado em Ciências Empresarias naIPS-PolytechnicInstitute of Setubal Portugal. Especialista em Engenharia de Produção - Sociesc/Joinville. Possui graduação em Curso Superior em Fabricação Mecânica e Curso Técnico emMecânica-SENAI/Luzerna.Atua como pesquisador na Linha Pesquisa Competitividade do Agronegócio no MPA - Unoesc. É professor do SENAI Luzerna e Joaçaba e UCEFF Faculdades de Chapecó e professor em Cursos Superiores Técnicos e de Qualificação Profissional. Tem experiência na área de Engenharia de Produção, atuando principalmente nos seguintes temas: Sistema de gestão da Qualidade, Gestão de Processos, PCP e Lean. Avaliador/revisor ad hoc da RACE - Revista de Administração, Contabilidade e Economia,detentor do ISSN on-line 2179-4936, com qualis B2.

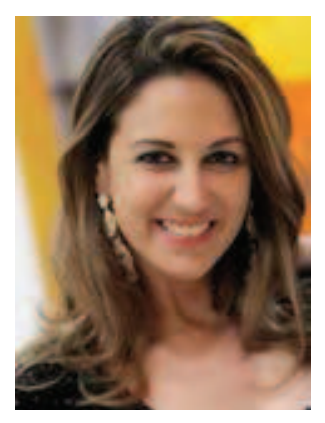

\section{Cristiane Duarte}

Administradora graduada pela Universidade do Oeste de Santa Catarina - Unoesc, Especialista em Marketing e alunadoMestradoProfissional em Administração daUnoesc. Docente nos cursos de Administração da Universidade Regional Integrada do Alto Uruguai e das Missões - URI (Frederico Westphalen-RS),UceffFaculdades (Chapecó-SC) e Celer Faculdades (Xaxim-SC).Docente em cursos dePós-Graduação/MBA, avaliadora/revisora ad hoc daRACE-RevistadeAdministração,Contabilidade 
e Economia, detentora do ISSN on-line 2179-4936, com qualis B2 em Administração, Contabilidade e Turismo. Atua como pesquisadora na Linha de Pesquisa: Sustentabilidade em Organizações no MPA - Unoesc. Consultora na área de Marketing.

\section{Lucimar Angela Frigeri}

Contadora graduada pela Fundação Educacional Unificada do Oeste de Santa Catarina - Fundeste, especialização em Controladoria e Finanças, Gestão de Pessoas, Contabilidade Gerencial e Custos pela Universidade do Oeste de Santa Catarina Unochapecó. Mestranda em Administração pela Universidade do Oeste de Santa Catarina-Unoesc. Atualmenteédocente daUnochapecó,Unoesc, Celer Faculdades e Senai. É Analista de Sistemas na empresa Questor Sistemas Ltda.

\section{***}

